\title{
PARODIANDO LA FRUSTRACIÓN DE LA SUPERWOMAN: LIZ LE- MON EN EL ENTORNO LABORAL DE ROCKEFELLER PLAZA
}

\author{
Elisa Hernández Pérez¹: Universidad de Valencia. España.
}

elisa.hdez88@gmail.com

\section{RESUMEN:}

El personaje protagonista de la ya finalizada sitcom Rockefeller Plaza (30 Rock, NBC, 2006-2013), Liz Lemon, puede definirse como la caricatura de un modelo de mujer que se siente fracasada por su incapacidad de "tenerlo todo", esa utopía conciliadora impuesta al género femenino casi desde su incorporación al mundo del trabajo. Liz es la jefa de guionistas de un programa de sketches humorísticos en directo de relativo éxito, un puesto de gran exigencia que trata de compaginar con una inexistente vida no laboral. Así, muchos de los gags recurrentes de la serie proceden de insistir en los desastrosos resultados de su torpeza a la hora de conciliar estas dos áreas de su caótica vida diaria, derivando en una enorme confusión entre los dos ámbitos.

Realizando un análisis genérico de la presentación del personaje, este breve estudio pretende analizar cómo la puesta en escena es empleada para insistir en este desorden que caracteriza a la protagonista de Rockefeller Plaza. Por otra parte, se realizarán algunos comentarios en torno a las frustrantes consecuencias del irreal modelo de superwoman capaz de resolver por sí misma todos los problemas (consiguiendo con ello un gran éxito profesional y personal) y al papel jugado aquí por la parodia de dicho estándar.

PALABRAS CLAVE: series de televisión, parodia, superwoman, análisis del discurso

\section{PARODYING THE SUPERWOMAN COMPLEX: LIZ LEMON IN THE WORKPLACE IN 30 ROCK}

\section{ABSTRACT:}

\footnotetext{
${ }^{1}$ Elisa Hernández Pérez: es licenciada en Historia del Arte por la Universidad de Salamanca y actualmente es becaria de investigación en el departamento de Teoría de los Lenguajes y Ciencias de la Comunicación de la Universidad de Valencia.

elisa.hdez88@gmail.com
} 
The main character in the situation comedy 30 Rock (NBC, 2006-2013), Liz Lemon, can be easily described as the explicit parody of a feminine stereotype, that of a woman who, unable to "have everything", feels frustrated. The possibility of reaching both a successful career and a happy and stable home has been imposed to women ever since their first inclusion in the workforce. Liz is the head writer for a live sketches television show, a demanding job she tries to combine with her non-existing personal life. Thus, most of the recurring gags of the show insist in the chaotic results of Liz's inability to unite those two areas of her daily life and the confusion that comes with it.

By analyzing the way the character is portrayed, this brief work tries to explain how the mise-en-scène is used to insist in the disorder that defines Liz Lemon. Using this, a commentary on the consequences of the superwoman complex utopia will be made, while also trying to state what role parody plays in this example.

KEYWORDS: television series, parody, superwoman, discourse analysis

\section{INTRODUCCIÓN}

La estereotipación y la reducción de las características de los diferentes individuos a un mínimo reconocible es una práctica habitual en los medios de masas, en gran parte para propiciar la identificación de los espectadores con los personajes mostrados en pantalla. Sin embargo, recientemente ha sido posible detectar un mayor énfasis en la complejidad de los protagonistas de series de televisión. Éstos son cada vez más ambiguos y llenos de matices y, en cierta medida gracias a esto, también más atractivos y fascinantes a ojos de la audiencia. Desde Tony Soprano hasta Don Draper, pasando por Walter White o Dexter Morgan, la televisión de los últimos años nos ha mostrado una enorme variedad de caracteres con contradicciones y desequilibrios inherentes a la propia naturaleza humana pero en cierta manera obviados en producciones anteriores. Los ejemplos femeninos, aunque sin duda cuentan con su propia idiosincrasia precisamente por enraizarse en una tradición de estereotipación muy diferente a la de estos personajes masculinos, no son ni mucho menos una excepción.

Liz Lemon, creada e interpretada por la conocida humorista Tina Fey, es el personaje principal de la sitcom norteamericana 30 Rock, emitida por NBC entre otoño de 2006 y enero de 2013. Se trata de una mujer en la treintena que tiene un exitoso puesto laboral como jefa de guionistas de un programa de televisión de sketches humorísticos en directo, llamado TGS. La principal intención de Liz a lo largo de los más de 130 episodios es conseguir conciliar el alto nivel de exigencia de este empleo con una feliz vida personal, que sin embargo es mostrada continuamente como desastrosa, haciendo que el personaje fracase continuamente en sus intenciones. Incapaz de separar estas dos áreas con claridad pero al mismo tiempo negándose a abandonar la ilusión de plenitud en ambos aspectos de su vida diaria, Liz es mostrada en todo momento como una mujer frustrada y desordenada, muy capaz en aquellas labores que se corresponden con su trabajo pero inepta en todos aquellos aspectos ajenos al mismo, desde las relaciones interpersonales hasta la higiene y cuidado personal. 
Por ello, y como veremos, gran parte del humor de la serie procede no sólo de este caos, sino de las confusiones que ella misma genera por proyectar su vida personal en el entorno profesional, creando así situaciones disparatadamente cómicas (acorde por supuesto con el género al que pertenece la serie y con un tipo de humor tendente al absurdo fácilmente relacionable con el modelo $S N L)$. Es decir, se satiriza en cierta manera la frustración generada a partir de la imposición sociocultural de un modelo de mujer autosuficiente y capaz de "tenerlo todo", es decir, de llevar una vida plena y satisfactoria gracias a una correcta combinación equilibrada de triunfos laborales y éxitos familiares. Liz Lemon sería, pues, una vuelta de tuerca más al estereotipo de superwoman, ya que no sólo muestra las negativas consecuencias de tratar de alcanzar este utópico modelo, sino que parodia las mismas.

Mediante un breve análisis de algunas secuencias, pretendemos mostrar cómo la propia puesta en escena de la serie, y en concreto la manera de presentar a Liz Lemon en relación con sus subordinados y su jefe en los espacios de trabajo, es empleada para insistir en este caos que la caracteriza. Para ello se han seleccionado algunas imágenes y momentos de las dos primeras temporadas de la serie, precisamente por ser las que presentan de un modo más claro las características definitorias de los personajes, ya que, a lo largo de las siete temporadas de 30 Rock y con el propósito de mantener la fidelidad de una audiencia y evitar las repeticiones, los protagonistas son sometidos a una serie de cambios en sus vidas personales (Liz llega, finalmente, a casarse con un hombre algo más joven que ella, en cierta manera un futuro "amo de casa" con quien adopta una pareja de adolescentes). Los elementos audiovisuales funcionarían así para enfatizar la incoherente mezcla de lo personal y lo laboral que la propia protagonista genera al interactuar con el resto de personajes, ayudando así a la sátira de este modelo de mujer frustrada por exageración de dicho desengaño.

Por supuesto, sobra decir que no se trata de un modelo totalmente novedoso en televisión, y resulta casi inevitable no citar como precedente más inmediato y tal vez conocido Ally McBeal (David E.Kelley, FOX, 1997-2002), la dramedia sobre las relaciones personales y laborales de una abogada algo atolondrada y con cierta tendencia a las alucinaciones. Al mismo tiempo podría ser interesante tener en mente otros ejemplos similares de mujeres inmersas en una cierta ansiedad por sentir descontrol sobre algunas áreas de su vida, como Nancy Botwin, la ama de casa de suburbio reconvertida en traficante de marihuana para sus pijos vecinos en Weeds (Jenji Kohan, Showtime, 2005-2012). Es necesario también considerar que el personaje de Liz Lemon, como autorreflexión de una frustración existente en gran parte de la población en las sociedades occidentales contemporáneas, presenta una enorme cantidad de características dignas de análisis que sin embargo aquí no serán mencionadas, ya que nos centramos en la confusión existente en cómo el personaje funciona en su entorno profesional al ser incapaz de establecer correctamente la línea divisoria entre su vida personal y laboral.

\section{EL SUPERWOMAN COMPLEX}

En el episodio piloto de 30 Rock, Jack Donaghy (Alec Baldwin), el nuevo jefe de Liz Lemon, tras observarla durante unos segundos, la define como "neoyorquina femi-

Revista de Comunicación de la SEECI. (Julio 2014). Año XVII (34), 50-64 
nista de tercera ola, con estudios universitarios, soltera y pretendiendo ser feliz al respecto, demasiado ocupada pero con pocas relaciones sexuales, que compra cualquier revista que diga 'saludable imagen personal' en la portada y cada dos años retoma el punto durante... una semana". Con este rápido y acertado resumen del personaje, la serie nos pone enseguida en situación al presentar lo fácilmente reconocible que es el modelo de frustración femenina que luego parodiará.

Durante la II Guerra Mundial, por escasez y necesidad de personal masculino, se produjo una muy significativa incorporación de la mujer a la fuerza de trabajo fabril e industrial. Pero es sobre todo a partir de los años 60s del siglo XX cuando una serie de factores llevan a que las mujeres comiencen a desvincularse de manera práctica del "hogar" (la arraigada idea de ser una buena ama de casa, esposa y madre como sus funciones principales) y a adquirir una cierta independencia como trabajadoras. El feminismo desarrollado desde mediados de dicha década y aproximadamente hasta los años 80, denominado generalmente "de segunda ola" (considerando la primera la adquisición de derechos de tipo legal de finales del siglo XIX y principios del siglo XX en los países occidentales) es especialmente insistente en la idea de igualdad sociocultural entre los sexos a todos los niveles. De ahí que enseguida una correcta y equilibrada incorporación de las mujeres al mundo laboral fuera una de las principales metas a conseguir.

Ha de tenerse en cuenta que en ningún momento esta creciente ambición de triunfo personal laboral llegó a sustituir al deseo tradicional de conformar una familia funcional, lo que implica que la mujer sea la responsable de mantener un hogar feliz. Recordemos que ésta es una imagen en la que la publicidad, el cine y la televisión no dejan de insistir a lo largo de estos años, aunque, paradójicamente, muestren un estilo de vida basado en un consumo masivo para el que son necesarios unos mayores ingresos económicos por familia. Así, se generalizó la idea de que la mujer seguía siendo ama de casa, madre y esposa, a lo que ahora debía añadir una carrera laboral. De esta manera, el trabajo asalariado quedó en cierta manera conformado como una adición al doméstico y no como una alternativa o elección, siendo sin embargo el primero el que es visto como el lugar de verdadera independencia y enriquecimiento personal de la mujer como individuo completo y autosatisfecho (ya que las labores del hogar era algo que las mujeres ya hacían).

Todo esto derivó en que los medios de masas comenzaran a reflejar, a finales de los 70 s y sobre todo en los años $80 \mathrm{~s}$, modelos de mujer que ya no remitían exclusivamente a una subordinación al hombre. De ahí que surja, sobre todo en el mundo de la publicidad, el estereotipo denominado habitualmente en sociología como superwoman (Shaevitz, 1988). Son personajes que, por una parte, tienen un enorme éxito profesional y la capacidad de desenvolverse adecuadamente en un competitivo lugar de trabajo, asumiendo así una ambición tradicionalmente asociada con la masculinidad. En ocasiones, incluso, al vincularse a estos entornos concretos presentan características en cierta manera masculinizadas, como capacidad emprendedora, creatividad, fuerza o agresividad, llegando a veces a una asexualización de algunos personajes femeninos, especialmente aquellos que abandonan su vida familiar en favor de la laboral. Por otro lado, la superwoman es capaz de atender su hogar, criar a sus hijos, atender a su marido e incluso de cuidar su propia imagen personal. La "buena mujer" es pues aquella que vive bajo presión pero es perfectamente capaz de aguan- 
tarla y canalizarla para conseguir realizar todo aquello que se propone. Se trata, por supuesto, de un ideal extremo e inalcanzable que sin embargo se expone como modelo a seguir a pesar de la obviedad de su irrealidad, que además sigue apareciendo como la meta definitiva y perfecta en la vida de toda mujer moderna, generando así un frustrante superwoman complex ("complejo de supermujer").

Así, esta cierta tendencia de los movimientos liberadores de la mujer (en cursiva porque, irónicamente, en este caso supone un encarcelamiento), conformada en torno a la supuesta capacidad femenina de dominar a la perfección tanto el trabajo doméstico como el asalariado, está desde el principio abocada al fracaso. Al fin y al cabo, este proyecto, que podemos denominar como "de conciliación", se presenta como un fin viable y deseable cuando es simplemente una utopía imposible de realizar. Tratar de establecer una imposibilidad como la que acabamos de explicar como un destino deseable y alcanzable sólo puede derivar en la conformación de sujetos frustrados por su incapacidad para llegar a una meta concebida como factible.

Sin embargo, y a pesar de estar ampliamente reconocido como un modelo irrealizable, la superwoman sigue siendo una imposición para un alto porcentaje de la población femenina en los países occidentales. De un lado, la cultura de masas insiste continuamente en la primacía e importancia de la familia por encima de los demás aspectos de nuestra vida (López-Pumarejo, 1986). Esto a su vez implica una especie de demonización del trabajo por parte del ser humano contemporáneo (no sólo las mujeres), pues la ambición laboral y una extrema dedicación a la misma se presentan como algunos de los elementos que le impiden tener una vida personal plena. Por el otro lado y paradójicamente, la mujer tiene la tendencia a aferrarse a su éxito profesional como el más claro signo de su completa liberación del opresor patriarcado, de modo que una dedicación exclusiva a las labores del hogar es vista en cierta manera como una prisión retrógrada, casi como una derrota moral. Al mismo tiempo, un total abandono de la pretensión de llegar a tener una satisfactoria vida personal y una familia a la que cuidar es, en parte, una renuncia a aquello que tradicionalmente la define como sujeto femenino (masculinizándola de manera irremediable). El resultado es una inevitable ansiedad: ni es posible alcanzar un equilibrio satisfactorio, porque siempre se querrá abarcar más en la vida personal o en el trabajo, ni la elección de un ámbito en detrimento del otro es una alternativa viable, lo que lleva a una renuncia inconsciente a ambos, por cuestiones que podemos denominar logísticas y que se reducen a la simple constatación de que el tiempo es escaso. En el caso sometido a análisis en este estudio, el personaje Liz Lemon, insistiremos en cómo la incapacidad que muestra continuamente para mantener una vida personal coherente y alejada de su espacio de trabajo la lleva por un lado a tratar de proyectar sus necesidades familiares en sus compañeros de profesión, en ese confuso y alocado intento de "tenerlo todo".

Por otra parte, este modelo femenino utópico y generador de frustración generalizada es fácilmente relacionable con otros conceptos que subyacen en las sociedades occidentales contemporáneas. Para empezar, el propio capitalismo como sistema se sostiene en parte sobre la idea de que el éxito socioeconómico es posible para todo individuo que se esfuerce lo suficiente, de manera que todo el mundo puede triunfar. Lo cierto es que esto es una falacia del discurso capitalista para ayudar a perpetuarse y desarrollarse, ya que el sentido común nos recuerda que para que una persona

Revista de Comunicación de la SEECI. (Julio 2014). Año XVII (34), 50-64 
pueda enriquecerse, otras muchas verán reducida su calidad de vida. Por otra, y en una dirección ontológica en la que quizás resultaría demasiado complejo adentrarse, es posible también poner en relación esta ansiedad de plenitud del superwoman complex con la posibilidad de autonomía y compleción del ser humano que presenta el modelo de sujeto racional y cartesiano. Al fin y al cabo, se trata también de un ideal inalcanzable, pues el ser humano funciona también de manera irracional, y su incesante búsqueda y persecución de deseos nunca satisfechos lo llevan a configurarse como un sujeto incompleto o, en un sentido lacaniano, escindido. El problema planteado previamente sobre esta variedad de frustración femenina no se aleja en exceso de la concepción del mito moderno de un sujeto coherente e independiente, un "ser", siendo precisamente el problema que no se asuma como mito sino como meta, llevando igualmente a una especie de ansiedad generalizada por la incapacidad de alcanzar dicha compleción.

Sin embargo, y especialmente en el caso del capitalismo, este tipo de utopías establecidas como posibilidades o fines a perseguir resultan tremendamente útiles a la hora de mantener o perpetuar un status quo concreto. En cierto modo, podría considerarse que tanto el modelo de superwoman como la obvia conclusión del mismo, el superwoman complex, son un nuevo modo de opresión, menos evidente que el patriarcado tradicional, pero igualmente coercitivo para el sujeto. Este sentido de control o poder, de índole foucaultiana, requiere de unas técnicas de disciplina cada más sutiles y discretas, insertas en elementos de nuestra vida cotidiana que normalmente consideramos anodinos o inocentes (Foucault, 1990).

Si consideramos, por otra parte, que vivimos dentro de sistemas culturales de significados, de manera que todo aquello que nos rodea es discurso ( $y$ el mundo nos llega en todo momento mediado por códigos significantes), conocer la manera en que dichas lógicas discursivas se configuran y nos son presentadas resulta de gran importancia para conocer las implicaciones de lo que vemos. De ahí la importancia de los modelos transmitidos por los medios de comunicación de masas, que son extremadamente simplificadores a la hora de presentar situaciones y personajes, ayudando así a crear una imagen estereotipada y alejada de la realidad en sus espectadores. Al fin y al cabo, los productos culturales de masas, como son las series de televisión (sobre todo con el boom experimentado por el formato en los últimos años), son al mismo tiempo un reflejo y un modo de perpetuar retroactivamente la ideología dominante, uno de los principales aparatos que ayudan a mantener la lógica discursiva del sistema y estructura social que los mantiene.

Aquí es donde podríamos entrar a considerar la función de algunas estrategias textuales a la hora de perturbar el significado o discurso subyacente en muchos de los mensajes que recibimos continuamente. El ejemplo elegido como corpus de análisis implica una parodia del modelo de mujer que sufre superwoman complex pero que, aún consciente de ello, tiene graves problemas para dejar ir el ideal que considera que debe alcanzar. En este caso se extrema hasta casi alcanzar la irrealidad la ansiedad que esta situación provoca en las mujeres, exagerando sus características con el fin de aumentar la comicidad. La parodia funciona así como una manera de liberar al modelo previo de sus connotaciones, dándole así un nuevo significado, en general con intenciones burlescas en relación al original. En cierta manera, sirve para reducir los niveles de gravedad de muchos de los temas que pasan por el filtro de este tipo

Revista de Comunicación de la SEECI. (Julio 2014). Año XVII (34), 50-64 
de humor, de manera que la parodia es "una actitud de lectura, una forma desenfadada y autoconsciente de enfrentarse a ciertas manifestaciones culturales" (Roas, 2009, cit. en Rey, 2011: 176). Es decir, emplearemos a Liz Lemon para preguntarnos cuál es la verdadera función de la satirización de este estereotipo femenino tan fácil de localizar en nuestra sociedad actual y cuáles son sus posibles consecuencias: ¿es simplemente una ejemplificación divertida de dicho modelo o consigue realmente superarlo?

Antes de proceder a la presentación de los ejemplos seleccionados, hemos de recordar una vez más que el personaje es lo suficientemente complejo como para permitir un análisis desde múltiples puntos de vista y temas a los que aquí no remitiremos por cuestiones de espacio (tales como, por ejemplo, su insistente auto-dessexualización), ya que nos centramos específicamente en cómo la puesta en escena insiste en la confusión que presenta entre su vida personal y la laboral, sobre todo en el tipo de relación que establece con sus compañeros de trabajo.

\section{EL EJEMPLO: LA CAÓTICA VIDA DE LIZ LEMON.}

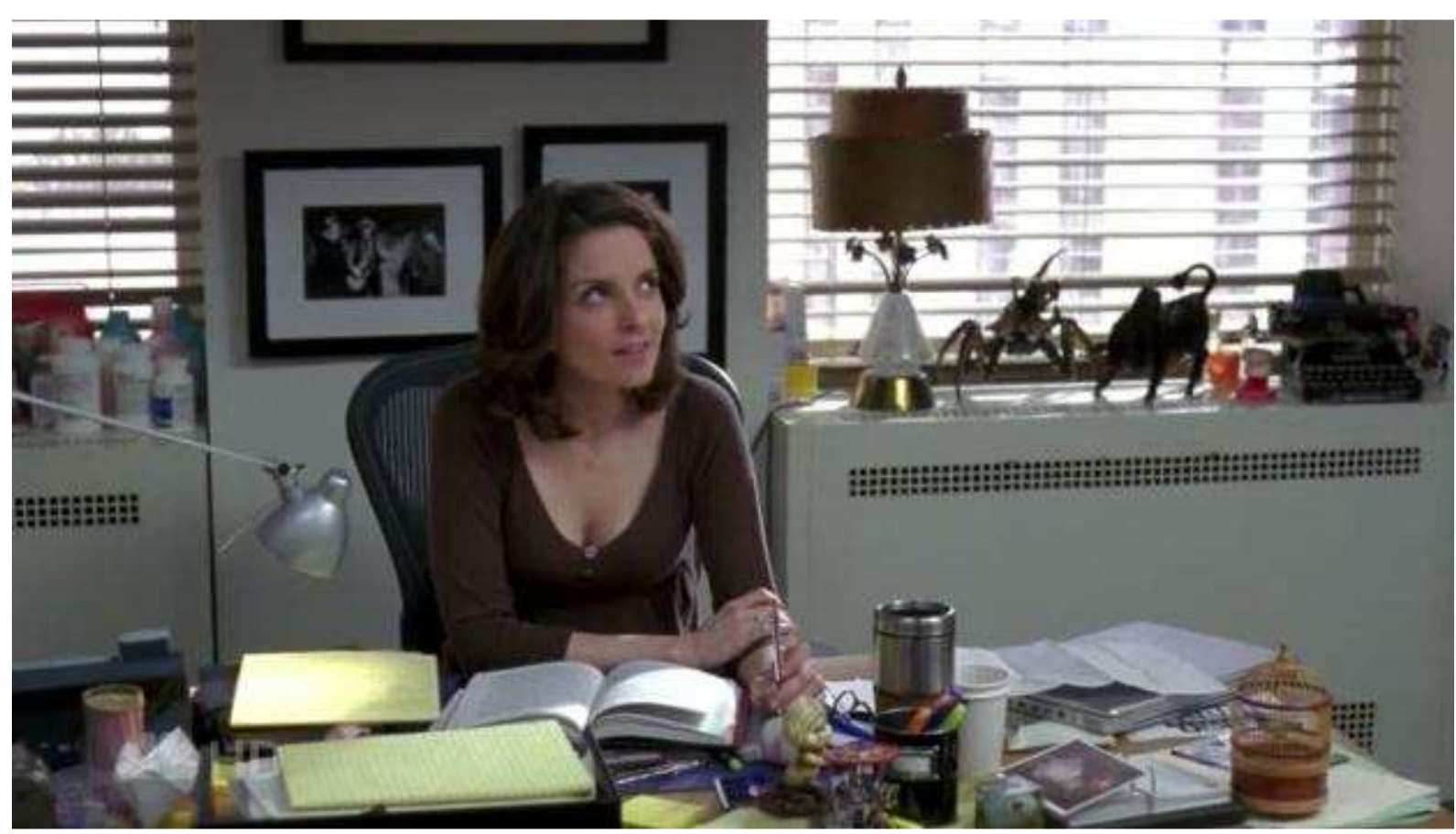

Foto 1.

Fuente: fotograma obtenido de la edición en DVD de la primera temporada de Rockefeller Plaza, Paramount Spain, S.L., 2009

Comenzaremos pues diferenciando los dos espacios más directamente relacionados con la protagonista: su hogar y su oficina. Siendo Liz Lemon la jefa de guionistas del programa de televisión en torno al cual giran la mayoría de tramas que vertebran cada episodio de 30 Rock, el personaje cuenta con un despacho propio al que se accede desde la sala principal de escritores. Aunque la decoración de este espacio varía a medida que avanza la serie, sí hay algunas características que se mantienen y que son visibles en la imagen, como la presencia de juguetes y objetos personales en los

Revista de Comunicación de la SEECI. (Julio 2014). Año XVII (34), 50-64 
alféizares de las ventanas (desde figuritas hasta, como se aprecia a la izquierda de la imagen, botes de medicamentos) y, sobre todo, la gran cantidad de papeles y trastos que se detectan encima de su mesa de trabajo, un caos asimilable, por supuesto, a la propia Liz. Aunque este fotograma está tomado de una escena concreta del octavo episodio de la primera temporada con lo que no sería adecuado emplearlo para generalizar, es posible señalar la actitud fantasiosa que indica su gesto, a pesar de encontrarse en horario laboral. Sí insistiremos en lo mucho que Liz Lemon aparece soñando despierta cuando tendría que estar trabajando (de hecho hay bastante gags a lo largo de la serie a partir de escenas imaginadas o incluso de recuerdos de la protagonista) y el hecho de que, en realidad, rara vez es vista en una verdadera actitud seria de tipo profesional. En general, da la sensación de que la protagonista simplemente corretea de un lado a otro, en continuo agobio, tratando de solucionar los diferentes y absurdos problemas que se presentan en la emisión de cada programa.

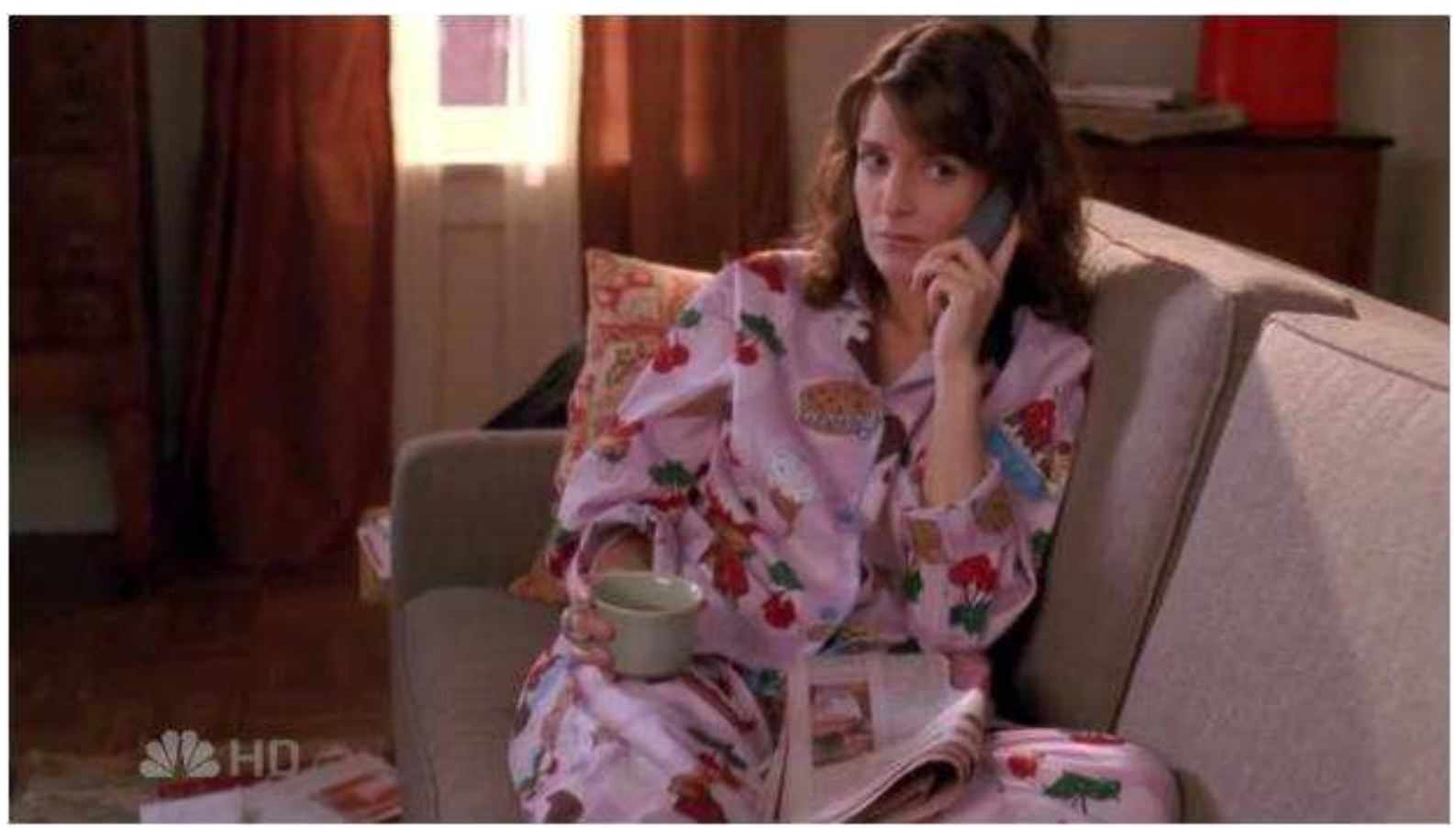

Foto 2.

Fuente: fotograma obtenido de la edición en DVD de la primera temporada de Rockefeller Plaza, Paramount Spain, S.L., 2009

Por oposición, el apartamento de Liz Lemon aparece en escasas ocasiones a lo largo de las primeras temporadas de la serie. Es en principio escenario de secuencias muy cortas y casi sin acción que no permiten dar al espectador una imagen coherente de la configuración del espacio, de manera que es percibido como un lugar tremendamente accesorio e innecesario para el desarrollo del personaje. La imagen que emplearemos aquí, tomada del octavo episodio de la segunda temporada, nos muestra a Liz en un breve flashback de recuerdo a uno de los múltiples momentos en que hace uso de su tiempo libre para satisfacer las necesidades personales de la actriz protagonista de TGS (el ficticio programa de sketches), Jenna Maroney (Jane Krakowski), también referida en ocasiones como la mejor amiga de Liz, a pesar de que

Revista de Comunicación de la SEECI. (Julio 2014). Año XVII (34), 50-64 
muy raramente coinciden fuera del entorno laboral. Como se explica en la escena (siendo de nuevo un chiste recurrente en la serie), Jenna tiene graves y exagerados problemas de autoestima, obligando a Liz a ir más allá de sus responsabilidades como jefa para tratar de ayudarla. En todo caso, es reseñable que lo poco que podemos percibir del hogar del personaje tiene un desorden similar al visto sobre la mesa del despacho (papeles en el suelo y en el mueble del fondo), y una menor cantidad de objetos de carácter personal, como fotos o figuritas.

A medida que avance la serie, el hogar de Liz adquirirá mayor importancia como escenario para convertirse en el lugar donde ocurren muchas de las tramas y subtramas de la serie. Sin embargo, el desorden nunca deja de acompañar a la protagonista, como refleja el hecho de que el personaje decida alquilar indefinidamente el apartamento inmediatamente superior al suyo para convertir su casa en un dúplex, pero que aún así las obras se alarguen a lo largo de varias temporadas a lo que luego se suma la repentina mudanza de su futuro marido. Esto propicia que las secuencias que emplean este entorno como escenario se vean a menudo repletas de cajas, trozos de madera o botes de pintura, insistiendo así en el caos y desorganización que rigen la vida personal de Liz, representada directamente en su hogar.

El deseo de la protagonista de ser madre es también un tema que aparece en varias ocasiones a lo largo de 30 Rock, como por ejemplo el momento en que decide apuntarse como madre soltera a una agencia de adopción, en la segunda temporada. Sin embargo, esta ilusión no se verá satisfecha hasta el último episodio de la serie, en que Liz y su marido acogen a dos niños que curiosamente recuerdan a Jenna y al otro actor protagonista de TGS, Tracy Jordan (Tracy Morgan), ambos emocionalmente muy exigentes. Durante las siete temporadas de 30 Rock, estos dos personajes son presentados como irresponsables e inmaduros que recurren insistentemente a Liz para solucionar sus ridículos problemas, lo que hace que ella tenga que vigilarlos en todo momento. En la siguiente imagen podemos ver un ejemplo del séptimo episodio de la serie en que Tracy se comporta de un modo irracional por no haber tomado sus medicinas a tiempo, mientras Liz intenta calmarlo para que pueda llevar a cabo una entrevista planificada.

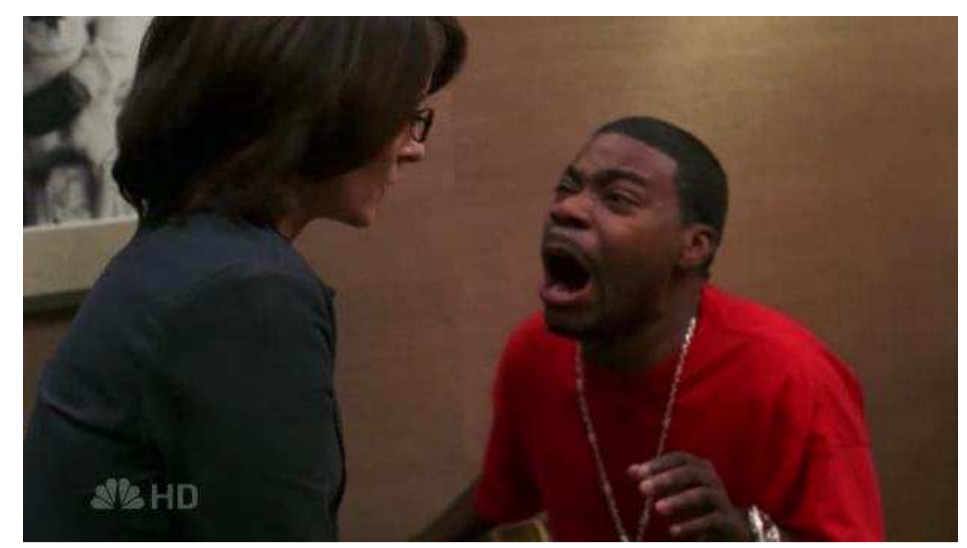




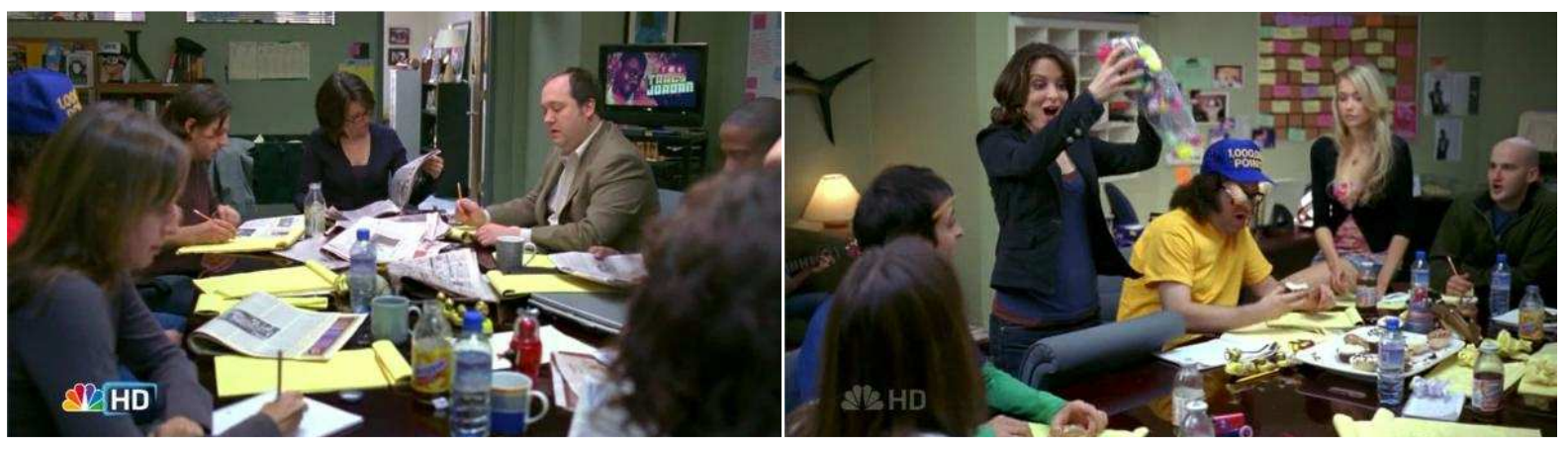

Fotos 3-5.

Fuente: fotogramas obtenidos de la edición en DVD de la primera temporada de Rockefeller Plaza, Paramount Spain, S.L., 2009

Liz adopta el mismo rol con sus subordinados, el resto de los guionistas del programa. La sala donde éstos trabajan se configura en torno a una enorme mesa en la cual se sitúan, con ella siempre presidiendo. De nuevo esta habitación presenta un cierto desarreglo y es posible señalar también gran cantidad de objetos, como juguetes, mezclados entre los desordenados papeles. Como demuestra otra escena de este mismo episodio, el número 14 de la primera temporada, su propia jefa fomenta este tipo de caos y de mezcla incoherente entre ocio y trabajo, manteniendo así un horario poco organizado (es normal, aunque forma parte del tipo de profesión, que se vean obligados a trabajar durante toda la noche previa a la emisión del programa). En la imagen Liz deja caer pelotas de colores sobre la mesa, haciendo que todos los guionistas se comporten de un modo excesivamente infantil al dejar lo que están haciendo de lado para perseguir los juguetes por toda la habitación. Es destacable también que sea ella la que ha traído las magdalenas que todos devoran ansiosamente y que vemos encima de la mesa, en un tiempo y un lugar que en teoría está destinado al trabajo.

Por una parte, estas imágenes nos permiten ver que la no separación entre la vida personal y profesional de Liz repercute en su puesto como jefa de un grupo de personas, haciendo que éstos tampoco tengan clara la división entre ocio y trabajo, siendo también una fuente de conflictos en gran cantidad de episodios de la serie. Por otro, se trata de una secuencia en que la protagonista llega a gritar "iqué jefa tan divertida tenéis!", mostrando así la necesidad que tiene de ser querida y apreciada por sus subordinados, algo a lo que dedica un gran porcentaje del tiempo de trabajo, en detrimento de tratar de ser valorada como profesional o competente (algo que, por supuesto, nunca ocurre). De ahí que, como reflejo a este modo de actuar, el grupo de guionistas sea presentado como insolente y malcriado, actitud que la propia Liz Lemon propicia con su errático comportamiento. Así, tan habitual como esta excesiva indulgencia es su posicionamiento como una madre estricta y represiva en relación al grupo de guionistas, actuando pues de un modo totalmente opuesto al presentado en el ejemplo anterior, llegando en ocasiones a alterarse como cualquier madre hastiada por tratar sin resultados de controlar a su inquieta prole. Al mostrar una falta de seriedad pero alta emotividad, Liz es claramente incapaz de comportarse como una verdadera jefa, falta que suple imitando actitudes maternales extremas a la hora de tratar a sus subordinados, los cuales, todo sea dicho, responden en todo

Revista de Comunicación de la SEECI. (Julio 2014). Año XVII (34), 50-64 
momento como niños. Por supuesto, no olvidemos que estas exageraciones extremas funcionan también a favor de la comicidad de tono absurdo de la propia serie.

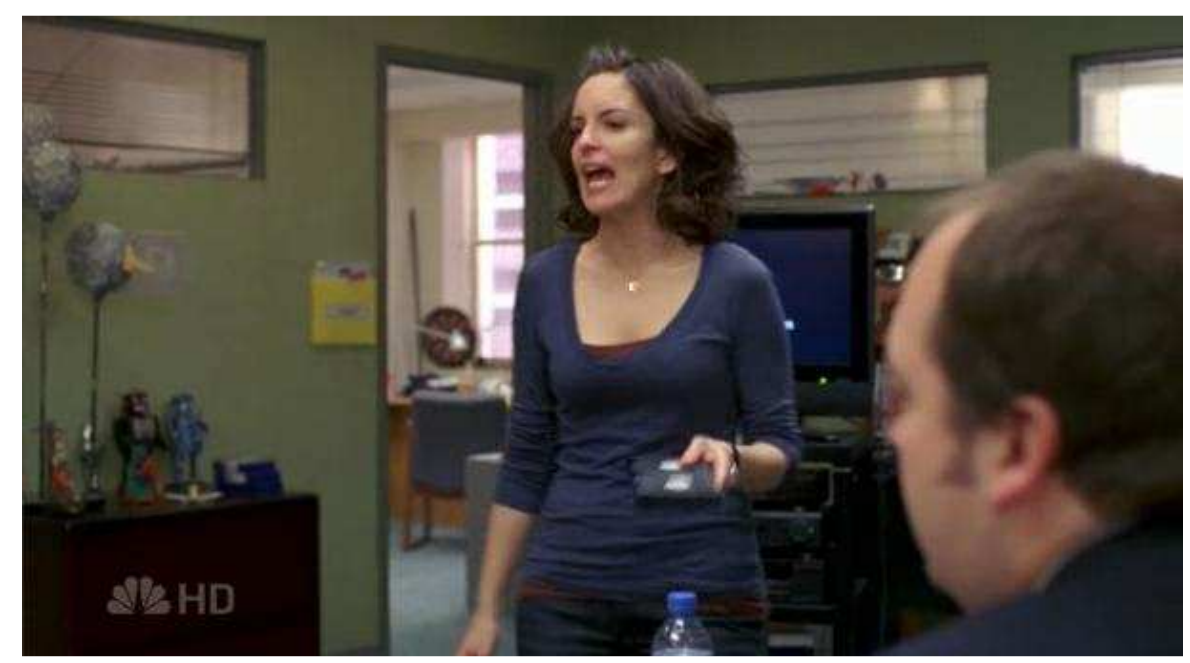

Foto 6.

Fuente: fotograma obtenido de la edición en DVD de la primera temporada de Rockefeller Plaza, Paramount Spain, S.L., 2009

Finalmente, una escena del cuarto episodio de la primera nos permite mostrar la confusa dependencia que Liz Lemon enseguida establece con su nuevo jefe, Jack Donaghy. En este caso, la protagonista busca en Jack una figura paternal que la proteja y aconseje en todos los ámbitos de su vida, de manera que tratan temas no sólo laborales sino sobre todo personales, ya que ella es, en numerosas ocasiones, incapaz de enfrentarse por sí sola a sus problemas (necesitando siempre los consejos de Jack). Se trata, al igual que con los subordinados-hijos, de una relación recíproca, ya que su propio jefe asume dicha función y responde como mentor de Liz. Sin embargo, la obvia diferencia es que mientras que ella es un personaje agobiado, frustrado y desordenado, Jack aparece, especialmente al inicio de la serie, como un exitoso y ambicioso profesional con un absoluto control sobre todos los aspectos de su vida, y una enorme actividad social vacía de sentimientos (en cierta manera, como hombre puede permitirse dejar de lado las responsabilidades hogareñas).

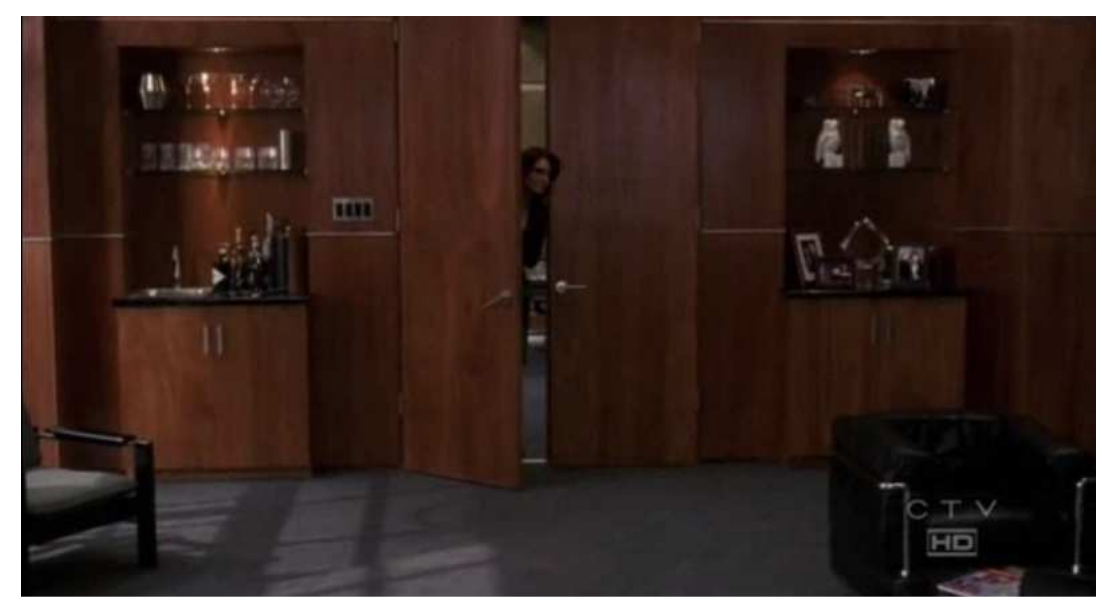

Revista de Comunicación de la SEECI. (Julio 2014). Año XVII (34), 50-64 


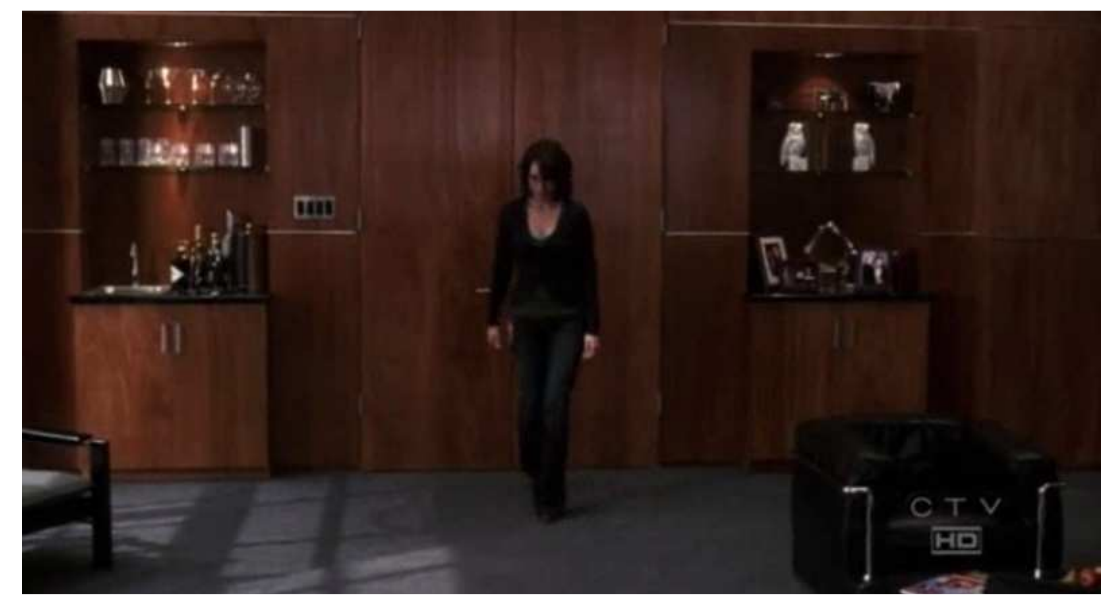

Fotos 7-8.

Fuente: fotogramas obtenidos de la edición en DVD de la primera temporada de Rockefeller Plaza, Paramount Spain, S.L., 2009

En esta secuencia, Liz llega al despacho de Jack para disculparse por un malentendido previo. El personaje se asoma a la inmensa puerta para acceder a la estancia, un enorme espacio en un amplio plano que ayuda a empequeñecerla, mostrándola al espectador como insegura y aniñada. Al tiempo que avanza lentamente hacia su jefe mientras se disculpa, su paso es torpe e infantilizado: la forma inclinada de asomarse a la puerta, la cabeza baja, las puntas de los pies orientadas la una a la otra y un balanceo de brazos prácticamente inexistente. Por el contrario, al ser visto situado tras un gran escritorio y frente a un enorme ventanal, Jack domina toda la habitación y se presenta como el punto de emanación del poder en esta situación concreta. Por una parte, la actitud de Liz estaría fuera de lugar en un entorno laboral, pues resulta no sólo pueril sino excesivamente íntima (sobre todo porque estamos todavía al inicio de la serie). Por otra, permite insistir en el abismo existente entre la autoridad de tipo maternal con que se enfrenta a sus subordinados y esta sumisa interacción con su jefe. El personaje muestra pues dos maneras opuestas de comportarse, ambas en exceso emocionales y poco profesionales, que encajarían más con el modo de actuar en un contexto familiar y cercano, del que, recordemos, Liz carece totalmente. Se insiste pues, en la muy exagerada esquizofrenia que la protagonista muestra en todo momento por sentir la necesidad de alcanzar un ideal imposible. Al ser incapaz de renunciar a su carrera, que le quita la posibilidad de desarrollar una satisfactoria vida personal, parecería que no tiene otro remedio que combinar inconscientemente ambas áreas, proyectando así sus necesidades afectivas en su entorno profesional, tanto con sus subordinados como con su supervisor. 


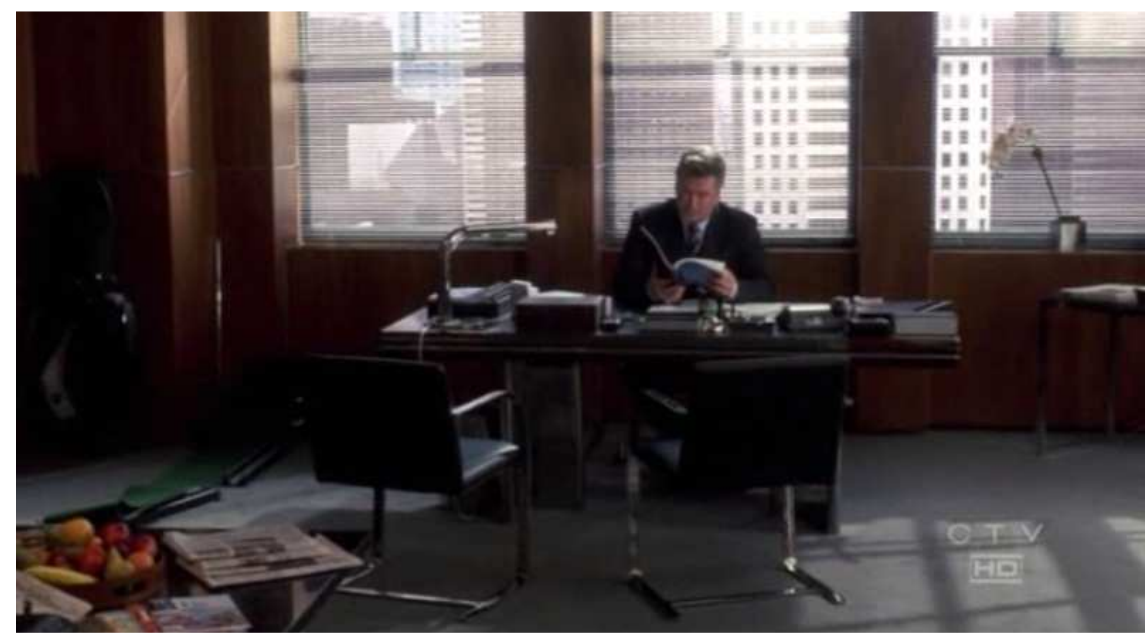

Foto 9.

Fuente: fotograma obtenido de la edición en DVD de la primera temporada de Rockefeller Plaza, Paramount Spain, S.L., 2009

\section{EN RESUMEN}

De nuevo, en este texto hemos empleado ejemplos concretos, pero es importante señalar que hay una enorme cantidad de secuencias, episodios o chistes recurrentes que podrían haber servido para transmitir la idea fundamental del texto: la explicación de cómo Liz Lemon es mostrada en pantalla como una exageración paródica de un modelo de mujer frustrada por la obvia incapacidad de "tenerlo todo". La protagonista queda conformada así como un personaje con una vida privada nula e incoherente y que presenta una serie de características desordenadas y caóticas tanto en su entorno como en la manera de comportarse, proyectando dichas faltas afectivas en una relación extraña con sus compañeros de trabajo.

Todo lo mencionado anteriormente nos lleva a preguntarnos si el satirizar las consecuencias del ideal de superwoman, haciendo burla de ella, ¿consigue superar dicho modelo o simplemente es una muestra más del mismo? Como conclusión, consideramos que la parodia ayuda a normalizar la frustración, pero sin realmente destruirla. Sin embargo, aunque no se proponga una solución al problema, sí que se desvela su construcción como discurso, el artificio, mediante su trivialización y exageración performativa. De esta manera se deconstruye y se muestra como mito y falsedad en lugar de insistir en su presentación como meta viable, colaborando en cierta manera a generar una mejor comprensión de la configuración de algunos de los modelos que forman parte de la ideología dominante, muchos de ellos impuestos como naturales a pesar de su artificialidad. 


\section{REFERENCIAS}

Duby, G. \& Perrot, M. (2000), Historia de las mujeres en Occidente, vol. 5. Madrid: Taurus

Ferrés, J. (1996), Televisión subliminal. Socialización mediante comunicaciones inadvertidas. Barcelona: Paidós

Foucault, M. (1990), Vigilar y castigar. Madrid: siglo XXI

Foucault, M. (2006), Historia de la sexualidad 1, la voluntad de saber. Madrid: Siglo XXI

Gubern, R. (1984), Estereotipos femeninos en la cultura de la imagen contemporánea. En Analisi, 9, 33-40

Internet Movie Database, recuperado de http://www.imdb.com/title/tt0496424/ (consultado el 13/11/2013)

López-Pumarejo, T.A. (1986), El discurso televisual: modelos culturales y vida cotidiana. En A. Cabanilles y V. Sánchez-Biosca (eds.), Metodología del Análisis de la imagen, Eutopias, 2, 1, 161-171

Mayayo, P. (2003), Historias de mujeres, historias del arte. Madrid: Cátedra.

Mulvey, L. (1976), Visual Pleasure and Narrative Cinema. En Screen, 16, 3, pp.618

Rey, E. (2011), "Are you 'aving a laugh", el post-humor y la nueva sitcom, en M.A. Pérez-Gómez (ed.), Previously on. Estudios interdisciplinarios sobre la ficción televisiva en la Tercera Edad de Oro de la Televisión, Universidad de Sevilla, pp.167-180

Shaevitz, M. (1988), The superwoman syndrome, Paperback.

Vilches, L. (1993), La televisión: los efectos del bien y el mal, Barcelona: Paidós.

Žižek, S. (2010), Mirando al sesgo. Una introducción a Jacques Lacan a través de la cultura popular, Barcelona: Paidós. 


\section{AUTORA:}

\section{Elisa Hernández Pérez}

Elisa Hernández Pérez (Santa Cruz de Tenerife, 1988) es licenciada en Historia del Arte por la Universidad de Salamanca. Tras finalizar el Máster en Historia del Arte y Cultura Visual de la Universitat de València en 2012 y el Máster en Interculturalidad y Políticas Comunicativas de la misma entidad en 2013, actualmente es becaria de investigación en el departamento de Teoría de los Lenguajes y Ciencias de la Comunicación, donde se encuentra realizando su tesis doctoral, que versa sobre la deconstrucción de la lógica discursiva capitalista en la serie de televisión "The Wire". 